\title{
Cedar Leaf Oil
}

National Cancer Institute

\section{Source}

National Cancer Institute. Cedar Leaf Oil. NCI Thesaurus. Code C80991.

The oil extracted from the foliage and wood of various conifers, especially Thuja occidentalis. Cedar oil is typically used for its aromatic properties. 